Supporting Information for

\title{
Hollow Cobalt Phosphide with N-doped Carbon Skeleton as Bifunctional Electrocatalyst for Overall Water Splitting
}

Yanyu Xie, Minqi Chen, Mengke Cai, Jun Teng, Huanfeng Huang, Yanan Fan, Dawei Wang*and Cheng-Yong Su

MOE Laboratory of Bioinorganic and Synthetic Chemistry, Lehn Institute of Functional Materials,

School of Chemistry, Sun Yat-Sen University, Guangzhou 510275, China.

\section{Corresponding Author}

*E-mail:wdawei@mail.sysu.edu.cn. 


\section{EXPERIMENTAL SECTION}

\section{CHEMICALS}

Cobalt nitrate hexahydrate $\left(\mathrm{Co}\left(\mathrm{NO}_{3}\right)_{2} \cdot 6 \mathrm{H}_{2} \mathrm{O}\right)$, 2-methylimidazole, and methanol were purchased from Alfa Aesar. 3-hydroxytyramine hydrochloride and Tris (hydroxymethyl) aminomethane (Tris) were purchased from Acros. Sodium hypophosphite and potassium hydroxide was purchased from Aladdin. All the reagents used in the experiments were of analytical grade and used without further purification.

\section{SYNTHESIS}

Synthesis of ZIF-67 nanocrystals. The method for ZIF-67 particles synthesis was based on the

literature reported. ${ }^{\mathrm{S} 1}$ In a typical synthesis process, cobalt nitrate hexahydrate $(4.0 \mathrm{mmol})$, and 2methylimidazole $(8.0 \mathrm{mmol})$ were dissolved separately in methanol $(50 \mathrm{~mL})$. The methanolic solution of 2-methylimidazole was mixed with the methanolic solution of cobalt nitrate hexahydrate under vigorous stirring, and then kept for $24 \mathrm{~h}$ without stirring. Purple precipitates were obtained and collected by centrifugation, washed with methanol three times and dried under vacuum at room temperature.

Synthesis of H-Co-LDH@PDA and Co-LDH. ZIF-67 nanocrystals (40 mg) and dopamine hydrochloride $(20 \mathrm{mg})$ were dispersed into $50 \mathrm{~mL}$ of Tris- $\mathrm{HCl}$ buffer solution $(10 \mathrm{mM}, \mathrm{pH}=8.5)$ with magnetic stirring for $3 \mathrm{~h} .{ }^{\mathrm{S} 2}$ The resultant product was collected via centrifugation and washed 
with deionized water and ethanol for three times, respectively. As for the synthesis of Co-LDH, ZIF-67 nanocrystals were transferred into a round bottomed flask containing cobalt nitrate $(0.1 \mathrm{~g})$ and ethanol $(25.0 \mathrm{~mL})$. Then the mixture was refluxed for $1 \mathrm{~h}$ under stirring. ${ }^{\mathrm{S} 3}$ Finally, the product was collected by centrifugation, washed with anhydrous ethanol, and dried at $60^{\circ} \mathrm{C}$ overnight.

Synthesis of H-CoP@NC, H-CoP and CoP/NC. To achieve phosphorization, H-Co-LDH@PDA (Co-LDH@PDA was replaced with Co-LDH or ZIF-67 if the target product was H-CoP or CoP/NC, respectively) and $\mathrm{NaH}_{2} \mathrm{PO}_{2}$ were placed at two separate positions in a closed porcelain crucible in a furnace while $\mathrm{NaH}_{2} \mathrm{PO}_{2}$ at the upstream side of the furnace. The samples were heated to $400{ }^{\circ} \mathrm{C}$ for $2 \mathrm{~h}$ at a heated rate of $5{ }^{\circ} \mathrm{C} / \mathrm{min}$ under argon atmosphere. ${ }^{\mathrm{S} 4}$

\section{CHARACTERIZATION}

The morphologies of all samples were examined with a field emission scanning electron microscope (FE-SEM, Hitachi, SU8010) operated at $1 \mathrm{kV}$ and $10 \mu \mathrm{A}$. Transmission electron microscopy (TEM) images, selected-area electron diffraction (SAED) patterns and energy dispersive X-ray spectroscopy (EDX) data were recorded on a JEM-ARM200P TEM operated at $200 \mathrm{kV}$. The powder X-ray diffraction (PXRD) patterns were collected on a Rigaku MiniFlex 600 X-ray diffractometer $(\mathrm{Cu} \mathrm{K \alpha})$. X-ray photoelectron spectroscopy (XPS) analysis were carried out on a Thermo ESCALAB 250XI X-ray photoelectron spectrometer. All XPS spectra were corrected against $\mathrm{C} 1 \mathrm{~s}$ peak at $284.8 \mathrm{eV}$ and the experimental data were fitted using XPS peak 4.1 software. 
Raman spectra were recorded on a HORIBA-iHR550 Raman Spectrometer using a $532 \mathrm{~nm}$ laser (Cobolt, Samba 25) as the excitation source. Nitrogen adsorption-desorption isotherms were obtained at $77 \mathrm{~K}$ with a Quantachrome Autosorb-iQ2-MP analyzer. Elemental analysis (EA) for determining the carbon and nitrogen content was performed on a 2400 Series II elemental analyzer (PerkinElmer, USA), and inductively coupled plasma (ICP) spectroscopy for quantifying the Co content was performed on an IRIS HR ICP spectrometer (Thermo Scientific, USA).

\section{ELECTROCHEMICAL MEASUREMENTS}

Electrochemical measurements were performed at room temperature $\left(25^{\circ} \mathrm{C}\right)$ using a threeelectrode setup n Metrohm Autolab electrochemical workstation, with carbon rod as the counter electrode and $\mathrm{Hg} / \mathrm{HgO}$ as the reference electrode. The catalysts were coated on a glassy carbon electrode (GCE; working electrode). All the measurements were performed in $1.0 \mathrm{M} \mathrm{KOH}$ solution $(\mathrm{pH}=14)$ that purged with $\mathrm{N}_{2}$ for 30 min prior to the HER (hydrogen evolution reaction) or overall water splitting test or with $\mathrm{O}_{2}$ prior to the OER (oxygen evolution reaction) test. Polarization data were collected at a sweep rate of $5 \mathrm{mV} / \mathrm{s}$. Electrochemical impedance spectroscopy (EIS) measurements were carried out by applying an AC voltage with $5 \mathrm{mV}$ amplitude in a frequency range from $100 \mathrm{kHz}$ to $10 \mathrm{mHz}$ at a potential of $1.55 \mathrm{~V}$ vs. RHE and of $-0.20 \mathrm{~V}$ vs. RHE in $1 \mathrm{M}$ $\mathrm{KOH}$ solution for OER and HER respectively. The potentials in our work were all transferred to the reversible hydrogen electrode (RHE) based on the equation given by $E_{\mathrm{vs} . \mathrm{RHE}}=E_{\mathrm{vs} . \mathrm{Hg} / \mathrm{HgO}}+0.059 \mathrm{pH}+0.098 \mathrm{~V}=E_{\mathrm{vs} . \mathrm{Hg} / \mathrm{HgO}}+0.921 \mathrm{~V}$. All the LSV data were calibrated with $90 \%$ 
iR compensation.

Preparation of working electrodes. The catalyst powder $(5 \mathrm{mg})$ was dispersed in water-ethanol mixed solvent $(1 \mathrm{~mL}, v / \nu=1: 1)$ solution contained Nafion solution $(20 \mu \mathrm{L})$. The mixture was then ultrasonicated for at least 30 min to generate a homogeneous ink. Next, the dispersion $(10 \mu \mathrm{L})$ was coated on GCE ( $5 \mathrm{~mm}$ in diameter) by dip coating to ensure a mass loading of $0.25 \mathrm{mg} / \mathrm{cm}^{2}$. The as-prepared film was dried at room temperature. As for overall water splitting, the ink $(50 \mu \mathrm{L})$ was coating on $\mathrm{Ni}$ foam $(1 \mathrm{~cm} * 0.5 \mathrm{~cm})$ to ensure the mass loading similar to that of GCE. 


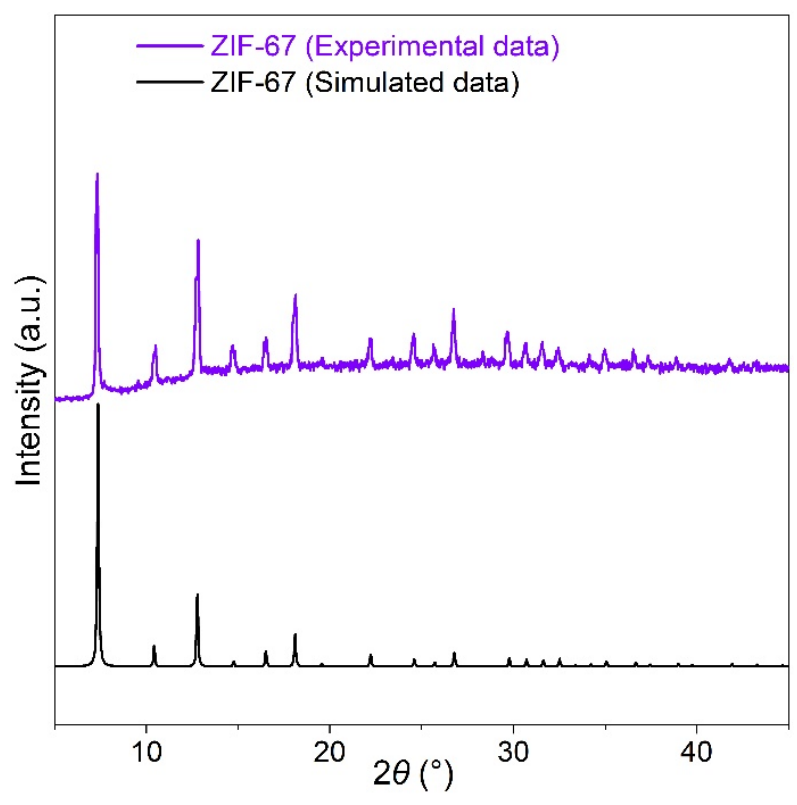

Figure S1. XRD pattern of ZIF-67.

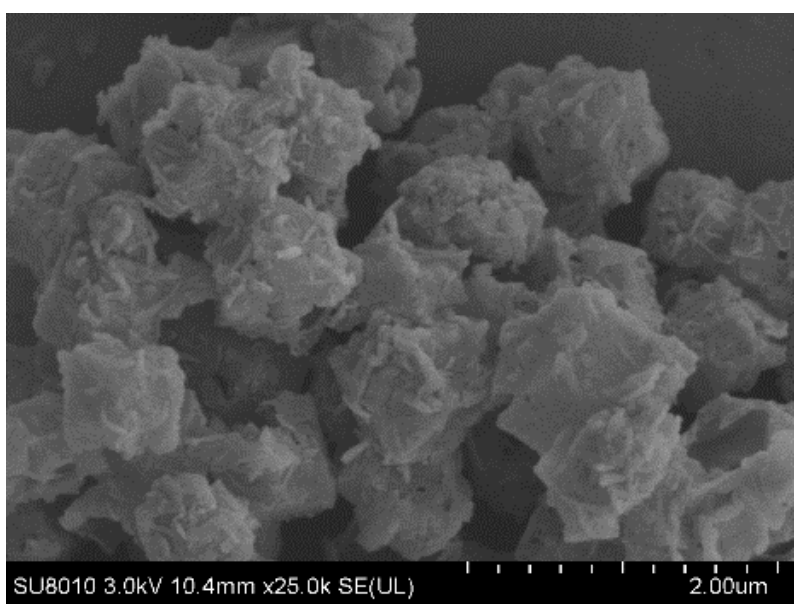

Figure S2. SEM image of H-Co-LDH@PDA. 


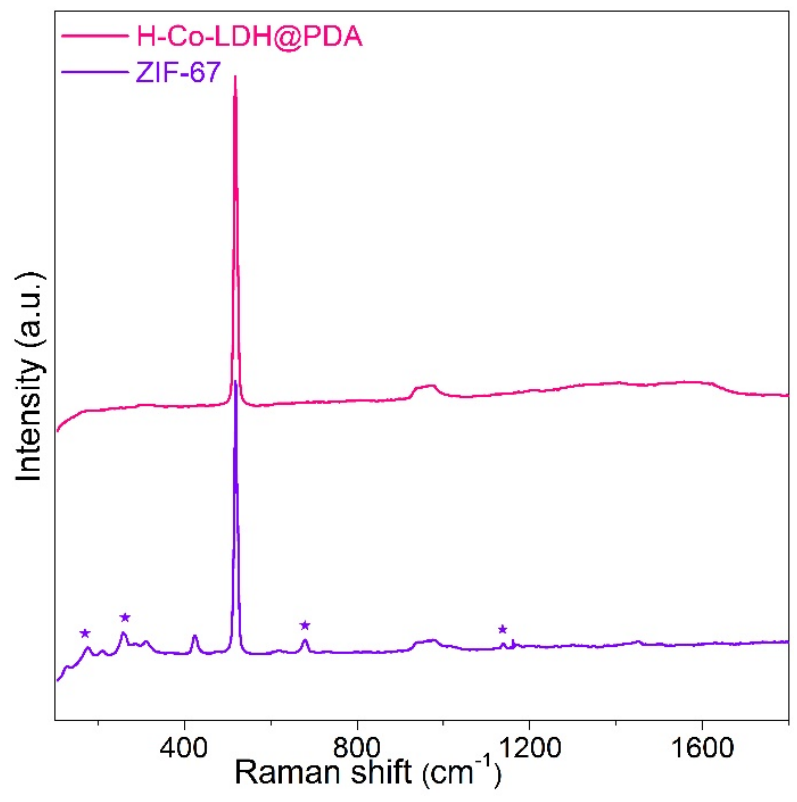

Figure S3. Raman spectra of ZIF-67 and H-Co-LDH@PDA.

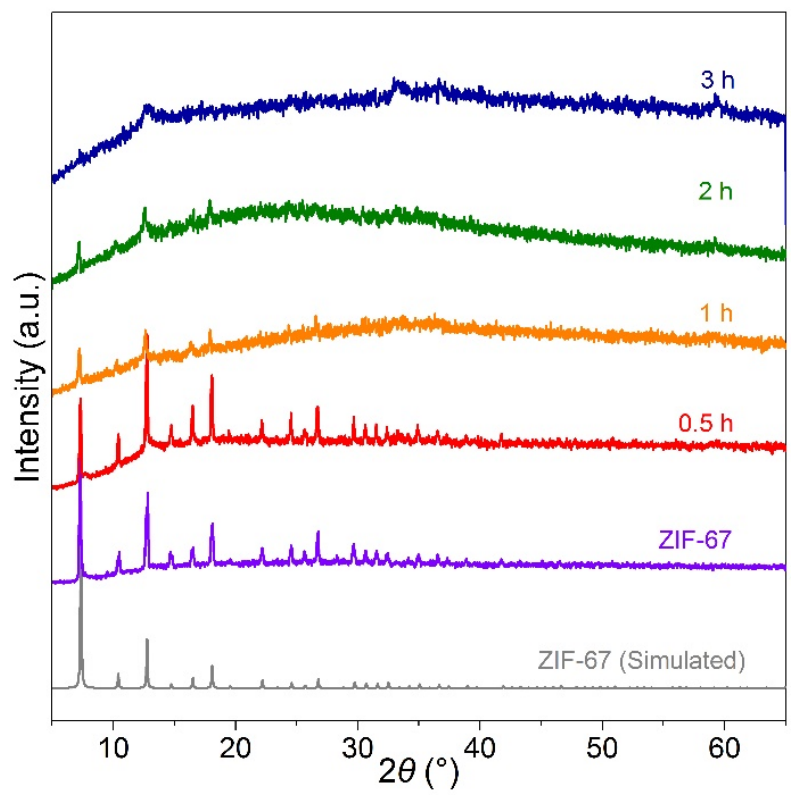

Figure S4. Time-dependent PXRD patterns of the products obtained during the PDA coating and ZIF-67 decomposition processes. 


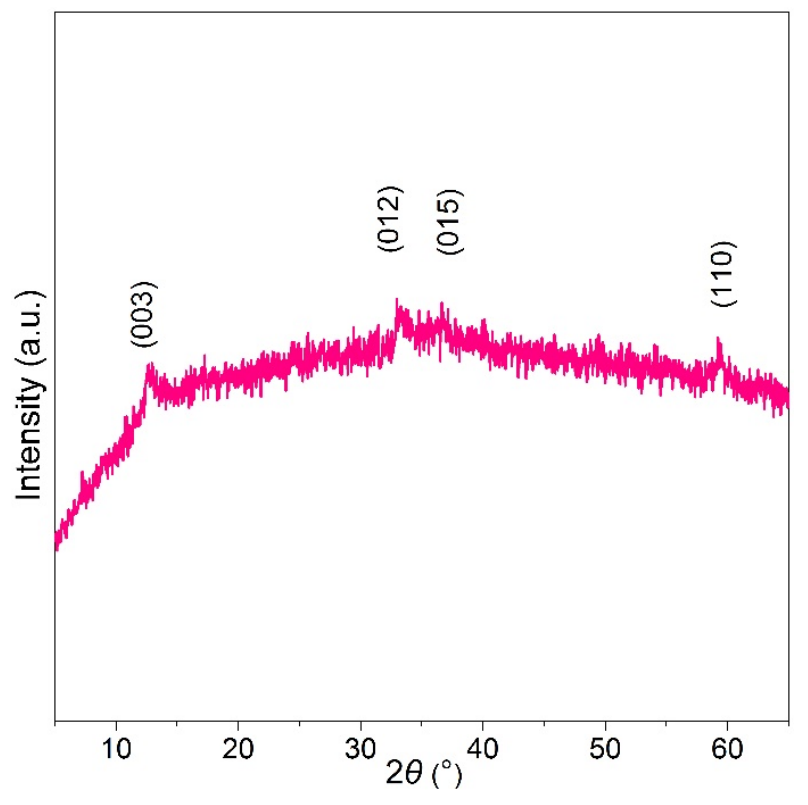

Figure S5. XRD pattern of H-Co-LDH@PDA.

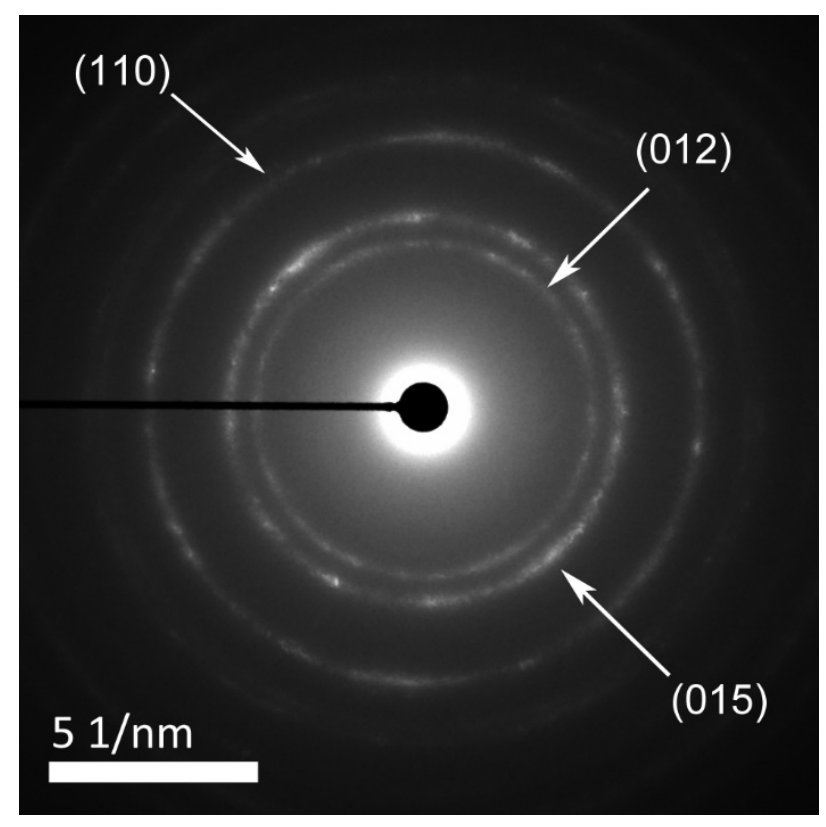

Figure S6. SAED pattern of H-Co-LDH@PDA. 


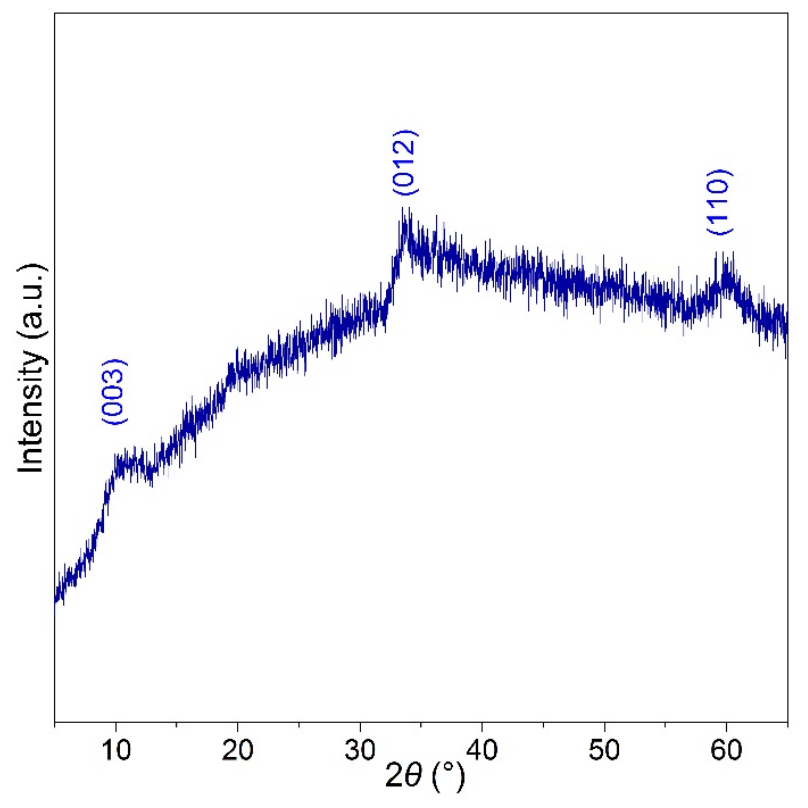

Figure S7. XRD pattern of Co-LDH nanosheets synthesized by immersing ZIF-67 powders into Tris- $\mathrm{HCl}$ buffer solution $(\mathrm{pH}=8.5)$ for $3 \mathrm{~h}$ without dopamine.

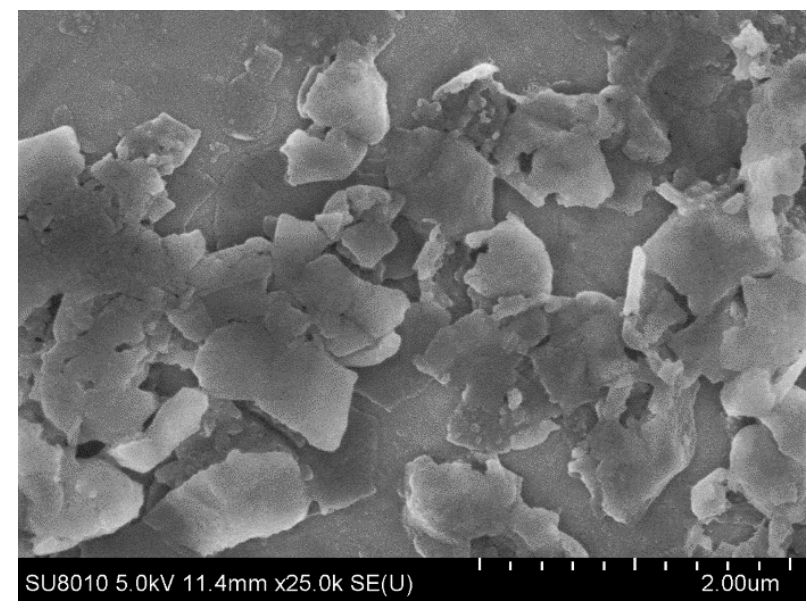

Figure S8. SEM image of Co-LDH nanosheets synthesized by immersing ZIF-67 powders into Tris- $\mathrm{HCl}$ buffer solution $(\mathrm{pH}=8.5)$ for $3 \mathrm{~h}$ without dopamine. 


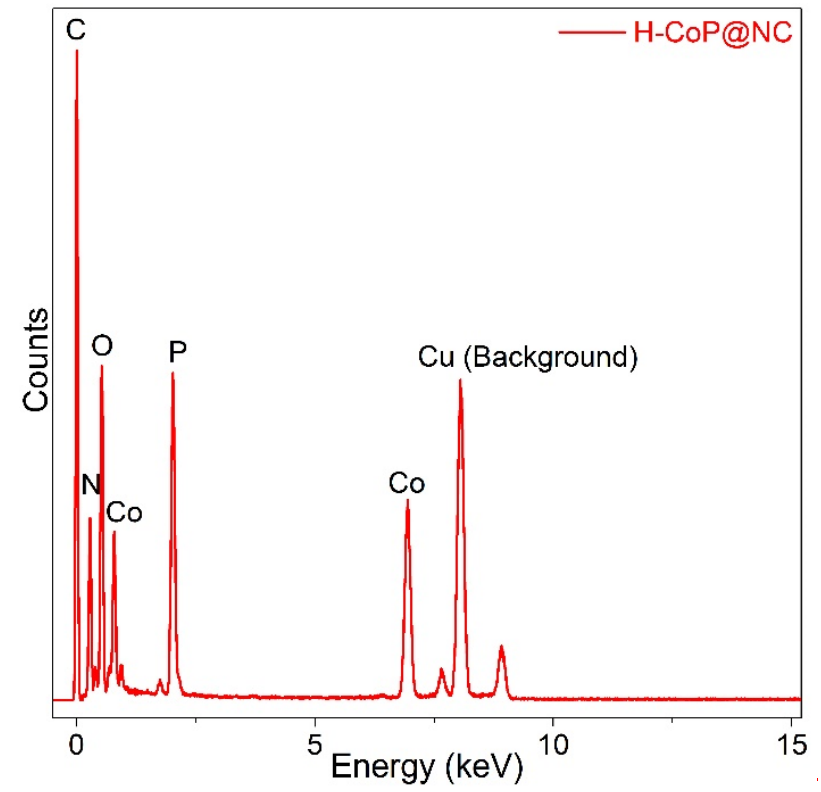

Figure S9. EDX spectrum of $\mathrm{H}-\mathrm{CoP} @ \mathrm{NC}$.

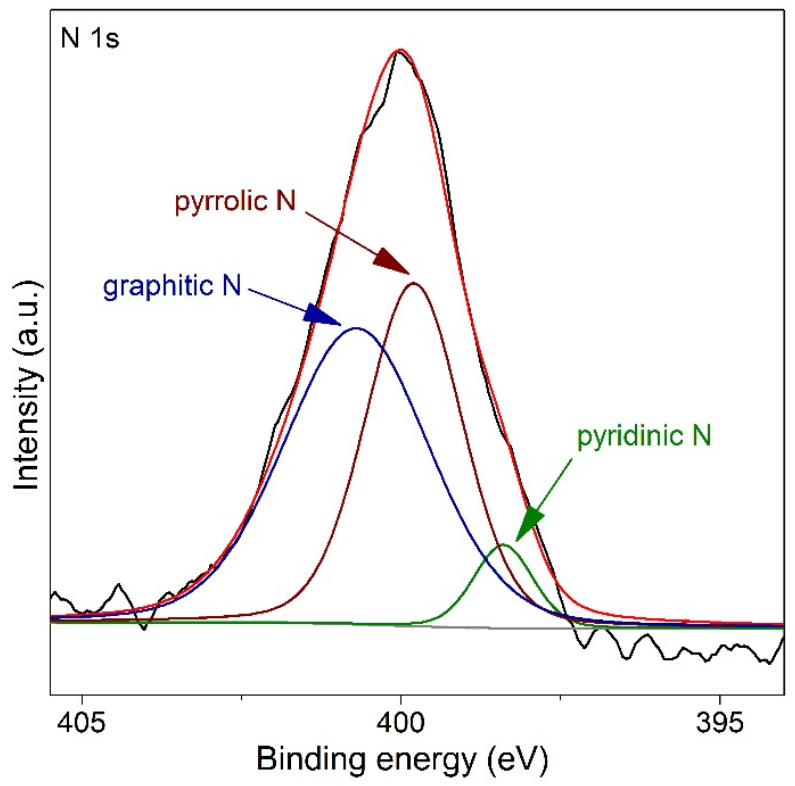

Figure S10. High resolution XPS spectrum of N 1s of H-CoP@NC. 


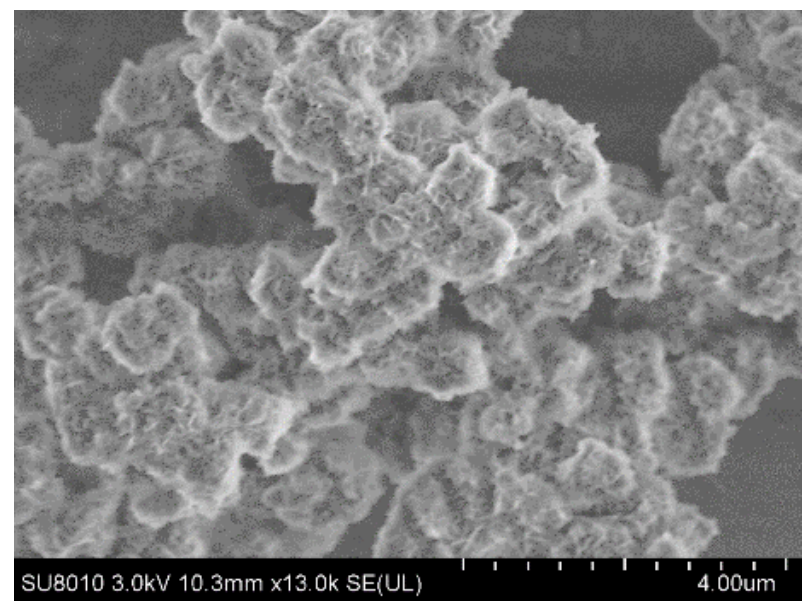

Figure S11. SEM image of Co-LDH (without PDA coating).

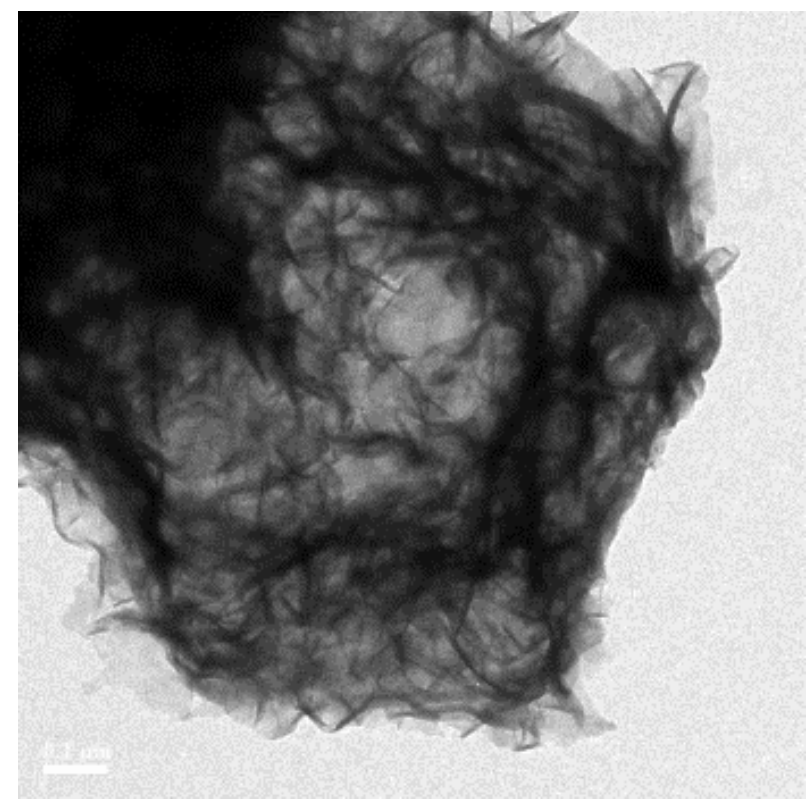

Figure S12. TEM image of Co-LDH (without PDA coating). 


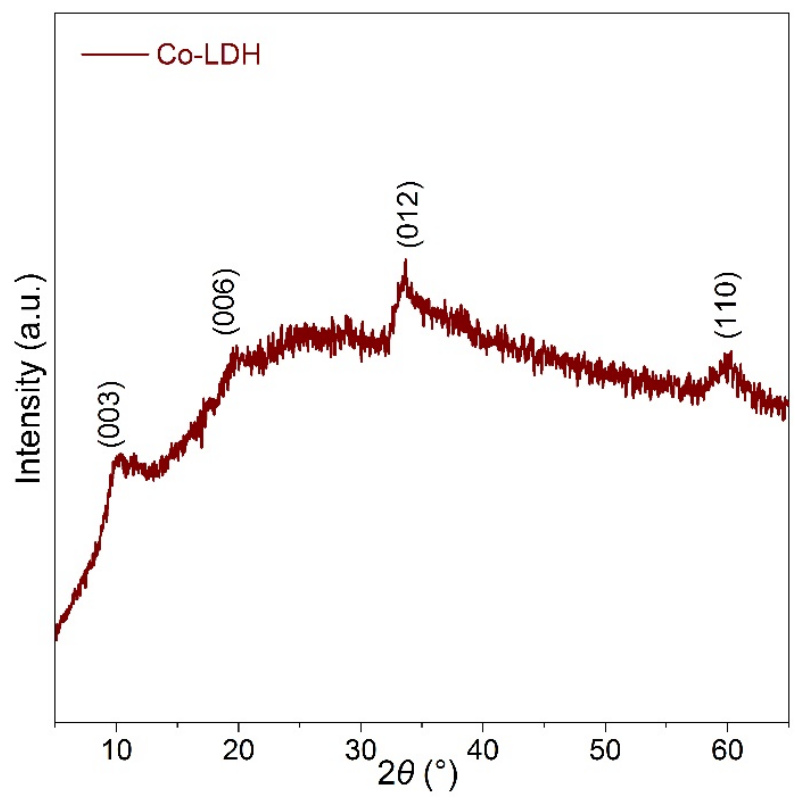

Figure S13. XRD pattern of Co-LDH (without PDA coating).

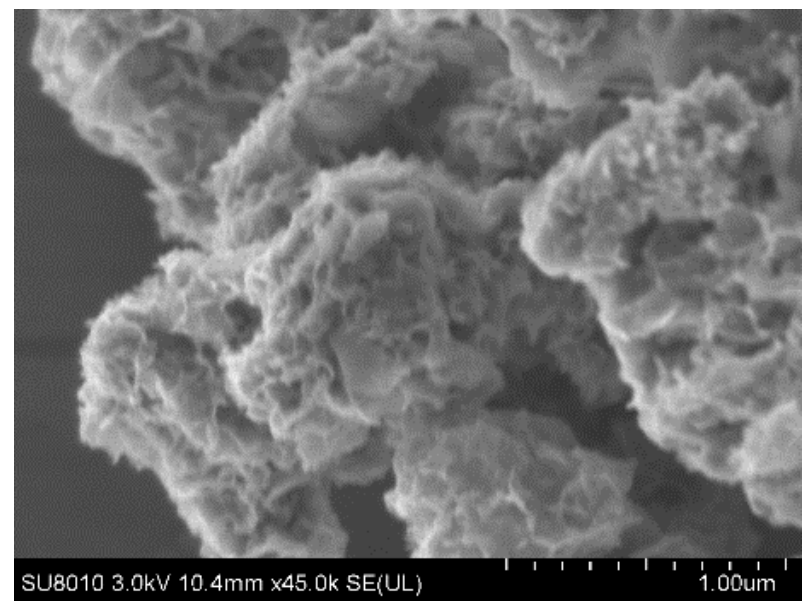

Figure S14. SEM image of H-CoP (without PDA coating). 


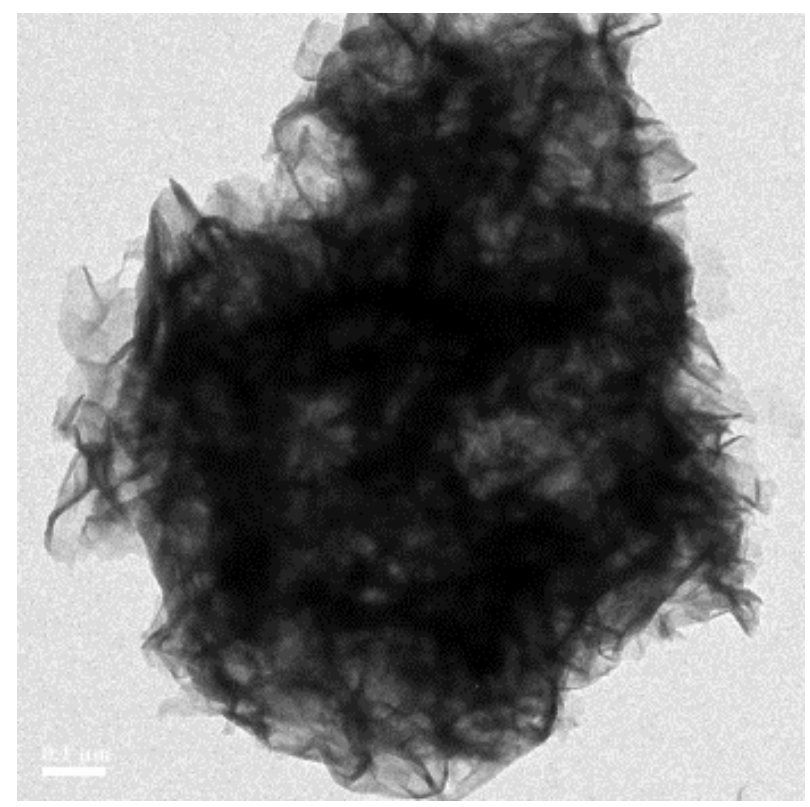

Figure S15. TEM image of H-CoP (without PDA coating).

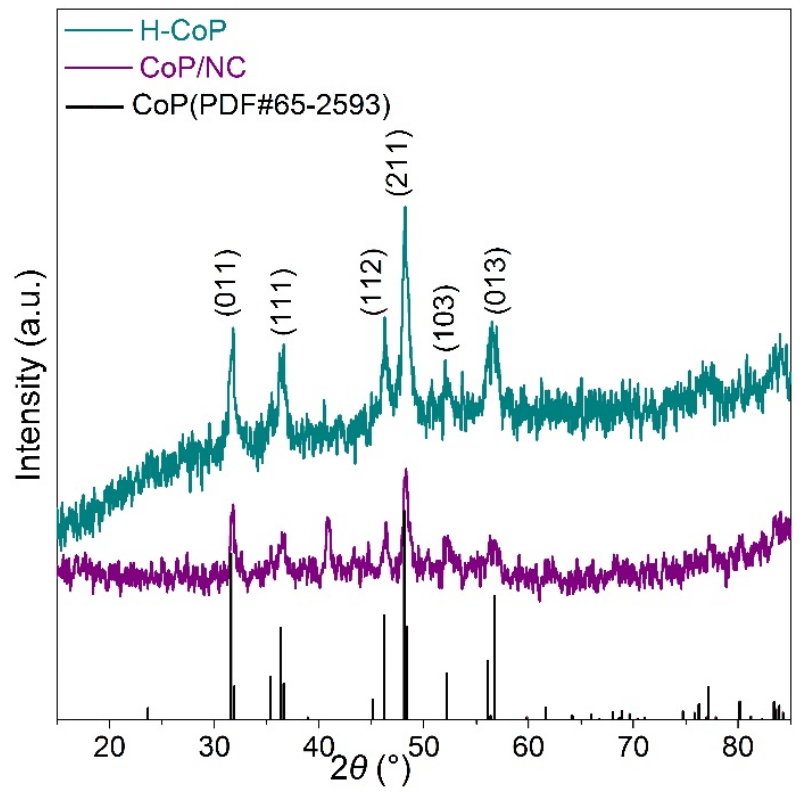

Figure S16. XRD patterns of $\mathrm{H}-\mathrm{CoP}$ and $\mathrm{CoP} / \mathrm{NC}$. 


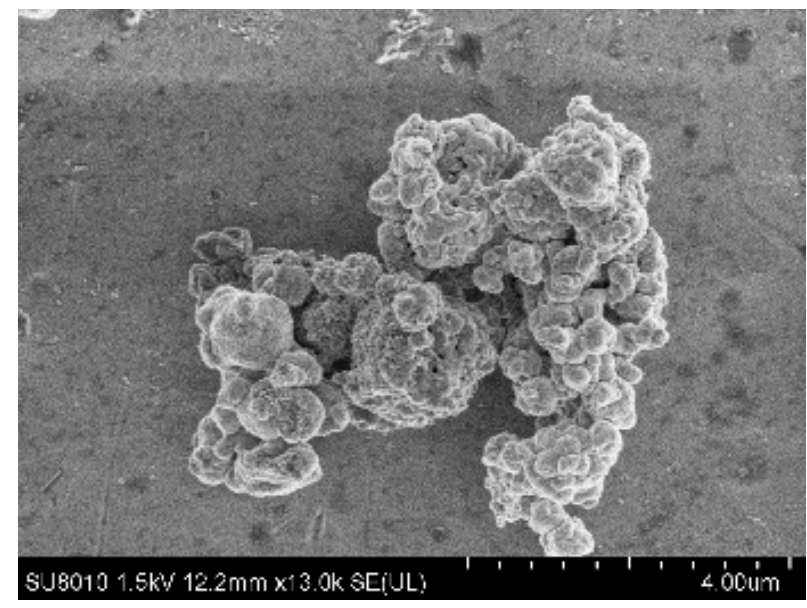

Figure S17. SEM image of CoP/NC synthesized by phosphorizing ZIF-67 without PDA coating.

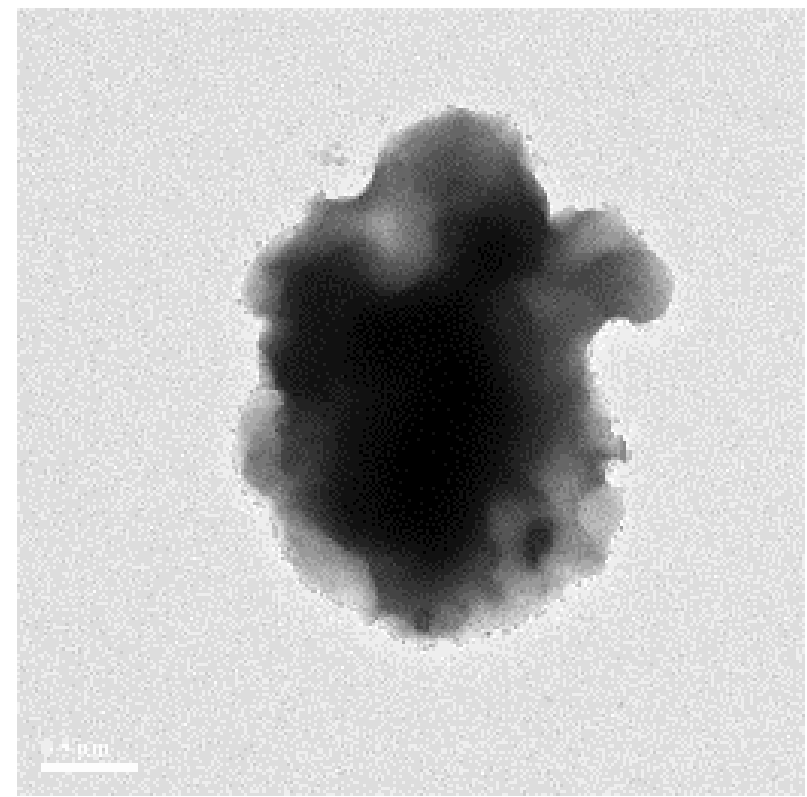

Figure S18. TEM image of $\mathrm{CoP} / \mathrm{NC}$. 


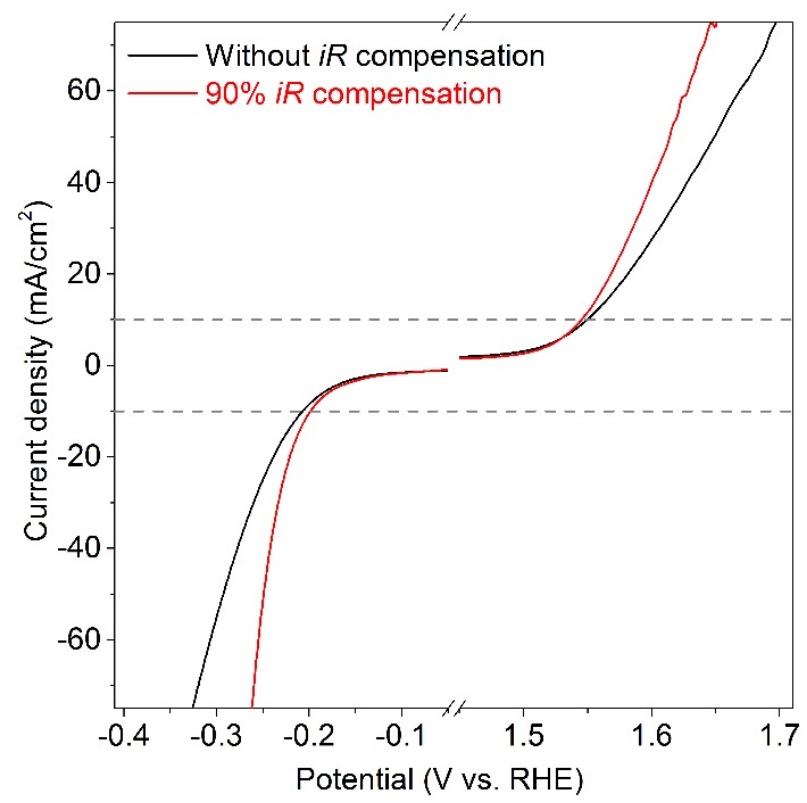

Figure S19. Polarization curves of H-CoP@NC (as the catalyst for HER and OER) with and without $90 \%$ iR compensation.

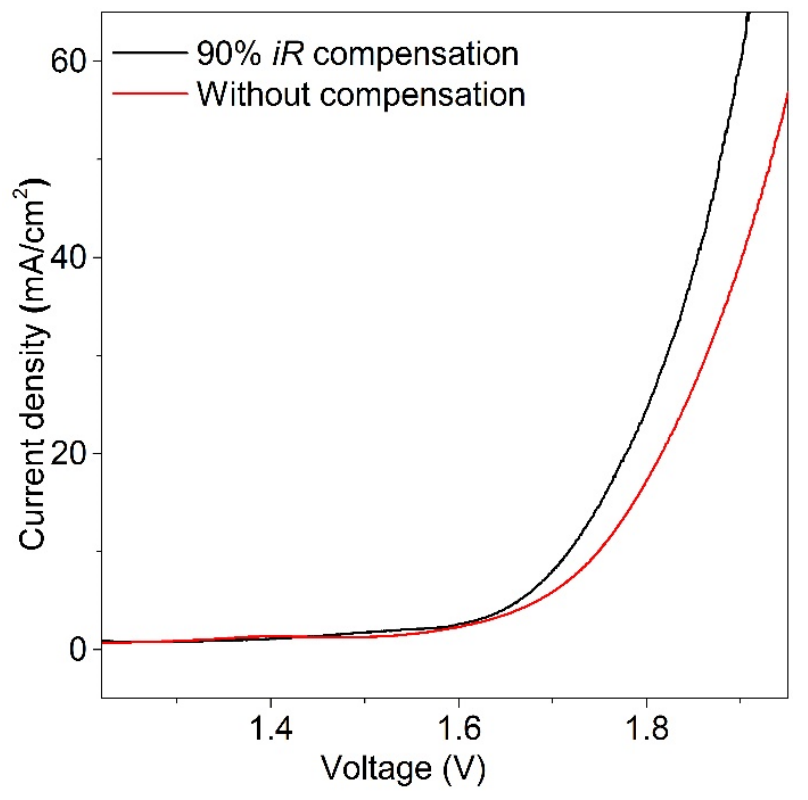

Figure S20. Polarization curves of H-CoP@NC (as the catalyst for overall water splitting) with and without $90 \%$ iR compensation. 


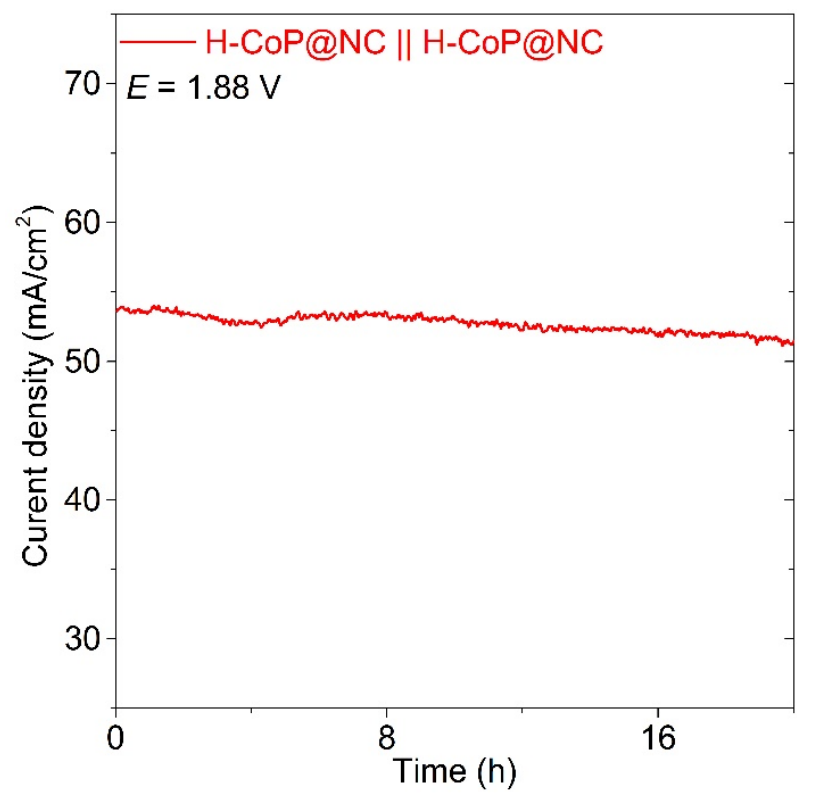

Figure S21. Current density of H-CoP@NC $\mid \mathrm{H}-\mathrm{CoP} @ \mathrm{NC}$ at a constant voltage of $1.88 \mathrm{~V}$ for 20

h.

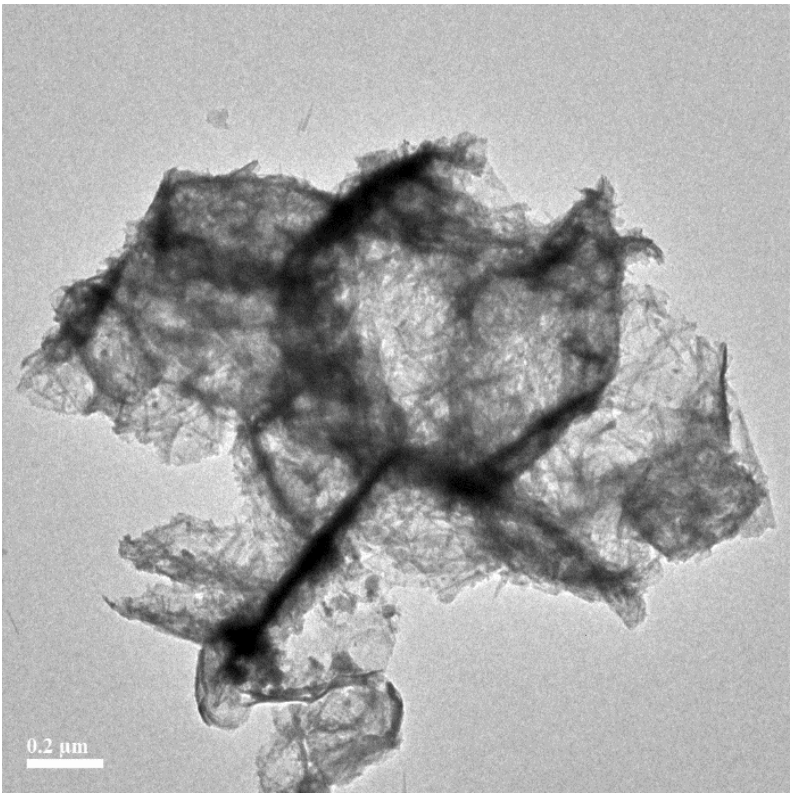

Figure S22. TEM image of H-CoP@NC as HER catalyst after 1000 LSV test cycles. 


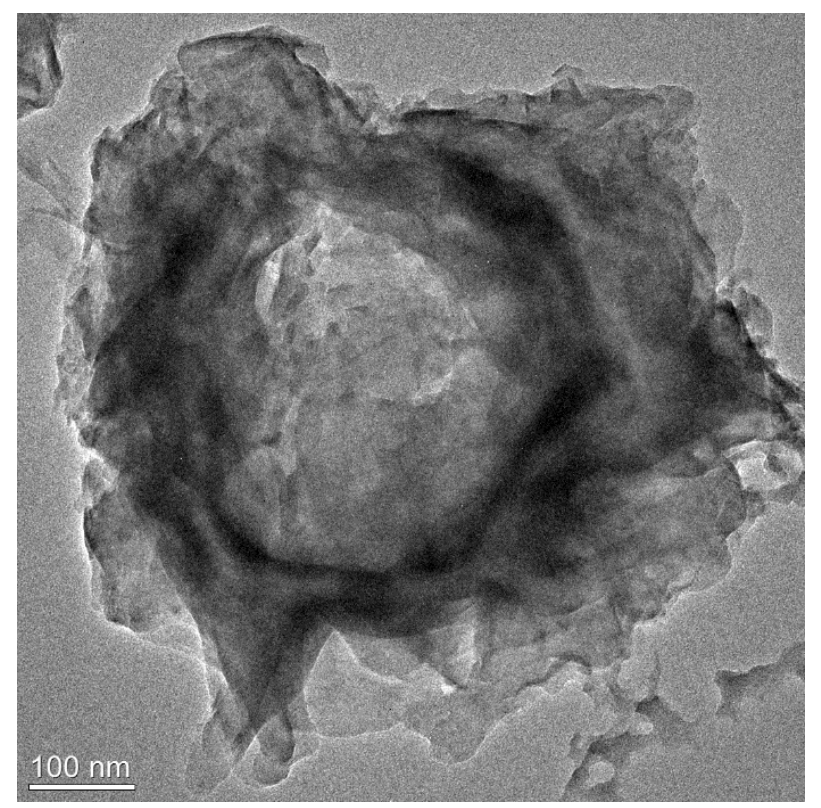

Figure S23. TEM image of H-CoP@NC as OER catalyst after 1000 LSV test cycles.

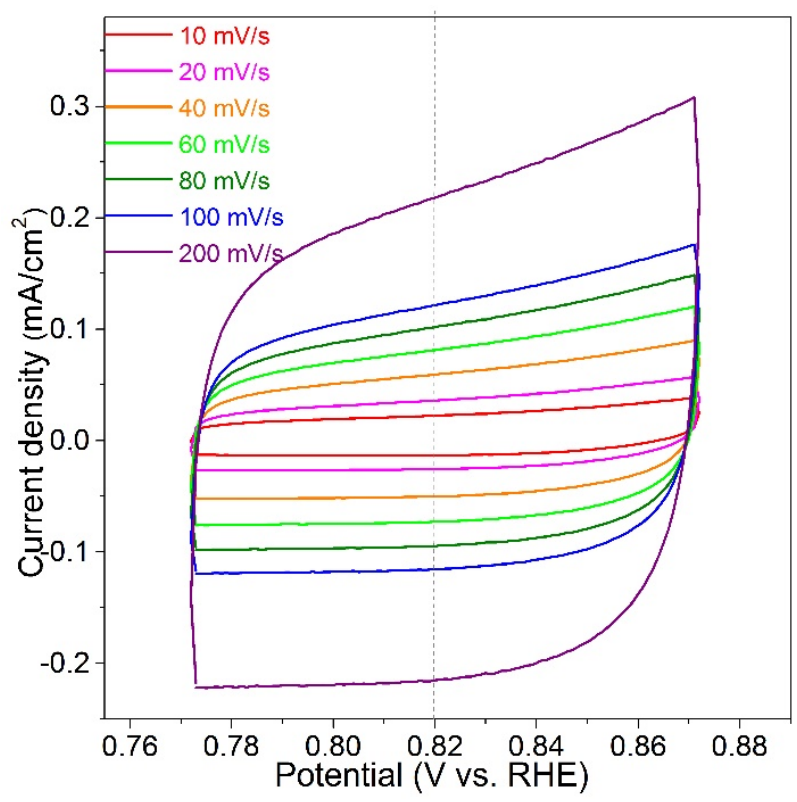

Figure S24. CV curves of $\mathrm{H}-\mathrm{CoP} @ \mathrm{NC}$ at different scan rates. 


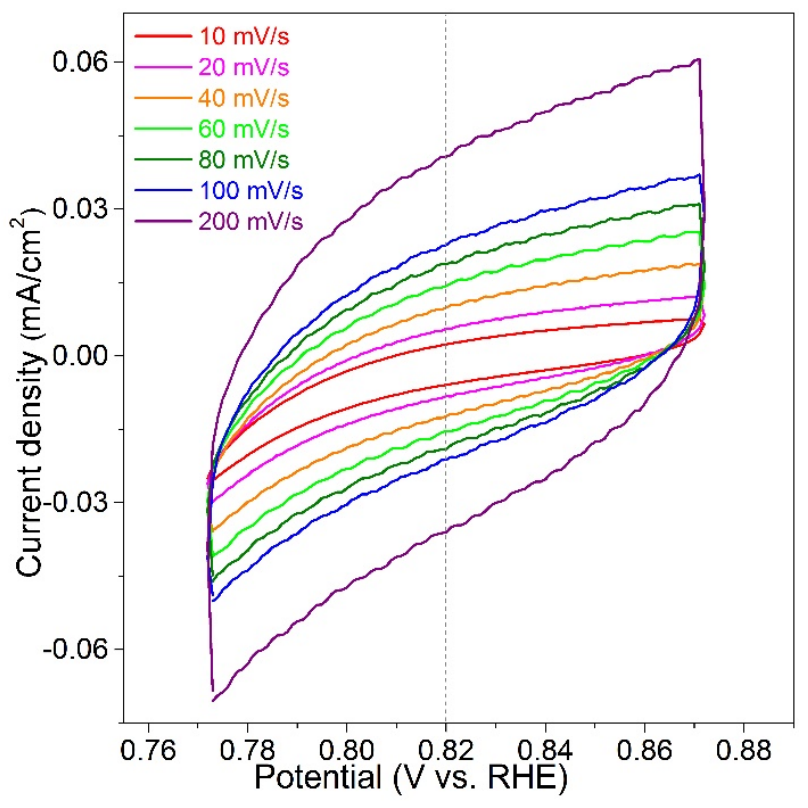

Figure S25. CV curves of $\mathrm{H}-\mathrm{CoP}$ at different scan rates.

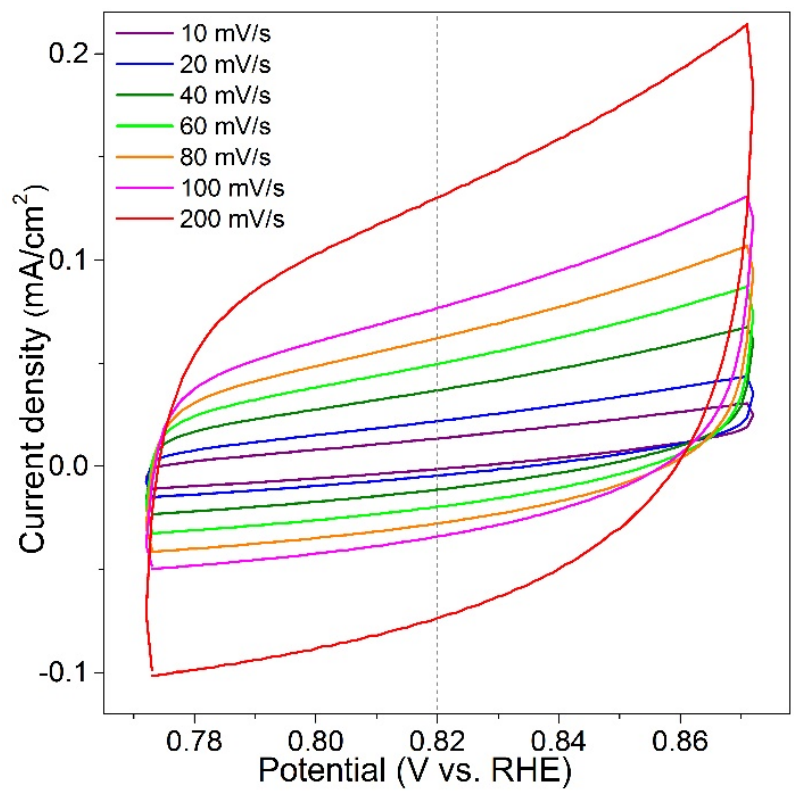

Figure S26. CV curves of $\mathrm{CoP} / \mathrm{NC}$ at different scan rates. 


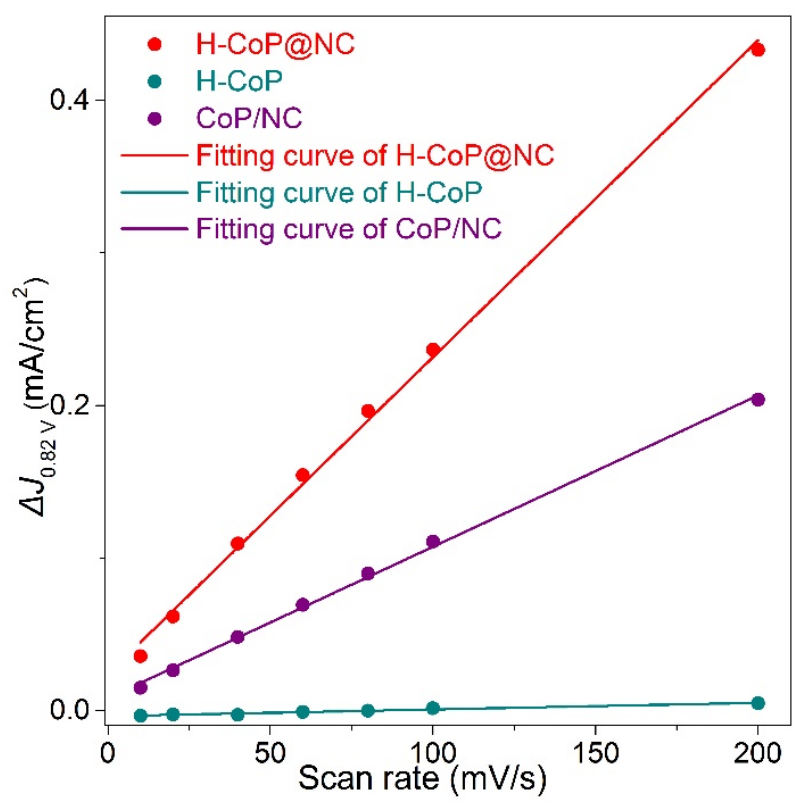

Figure S27. Fitting curves of $\mathrm{H}-\mathrm{CoP} @ \mathrm{NC}, \mathrm{H}-\mathrm{CoP}$ and $\mathrm{CoP} / \mathrm{NC}$.

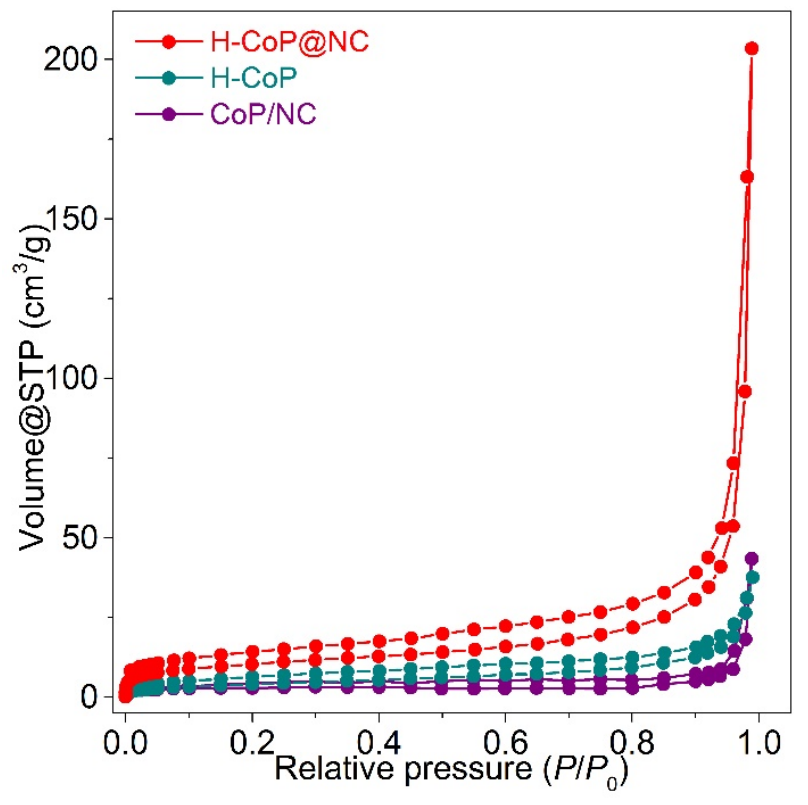

Figure S28. $\mathrm{N}_{2}$ adsorption-desorption isotherms of $\mathrm{H}-\mathrm{CoP} @ \mathrm{NC}, \mathrm{H}-\mathrm{CoP}$ and $\mathrm{CoP} / \mathrm{NC}$. 


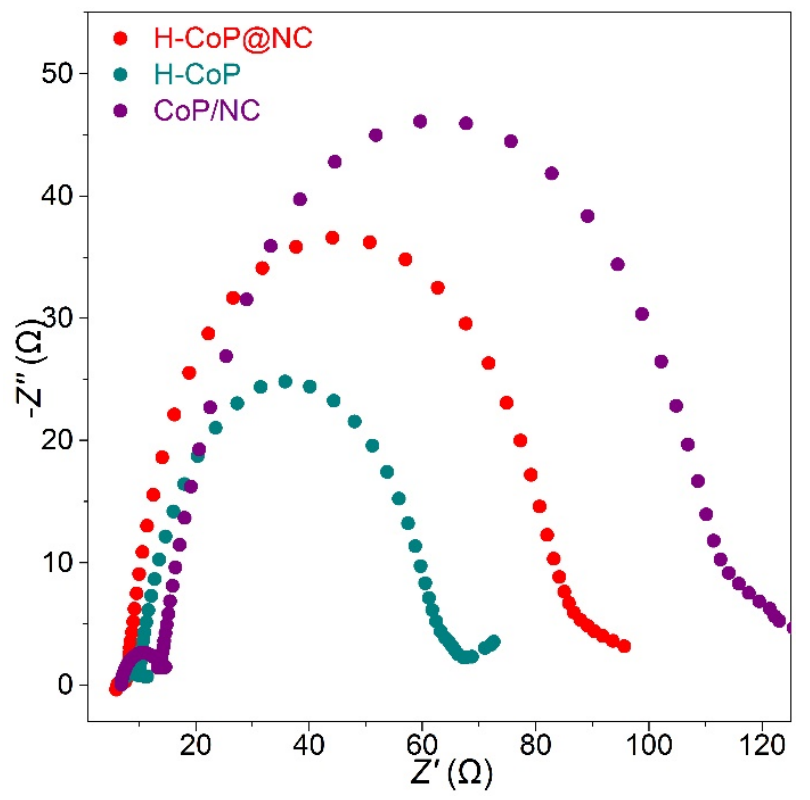

Figure S29. Nyquist plots of H-CoP@NC, H-CoP and CoP/NC for OER in 1.0 M KOH $(E=1.55$

V vs. RHE).

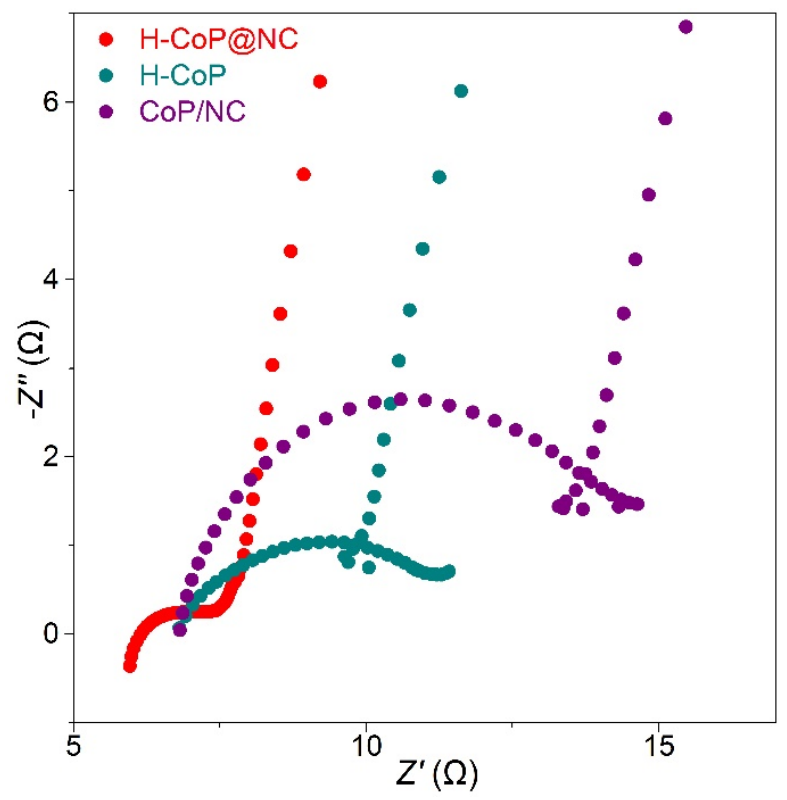

Figure S30. Nyquist plots (magnified) of $\mathrm{H}-\mathrm{CoP} @ \mathrm{NC}, \mathrm{H}-\mathrm{CoP}$ and $\mathrm{CoP} / \mathrm{NC}$ for OER in $1.0 \mathrm{M}$ $\mathrm{KOH}(E=1.55 \mathrm{~V}$ vs. RHE). 


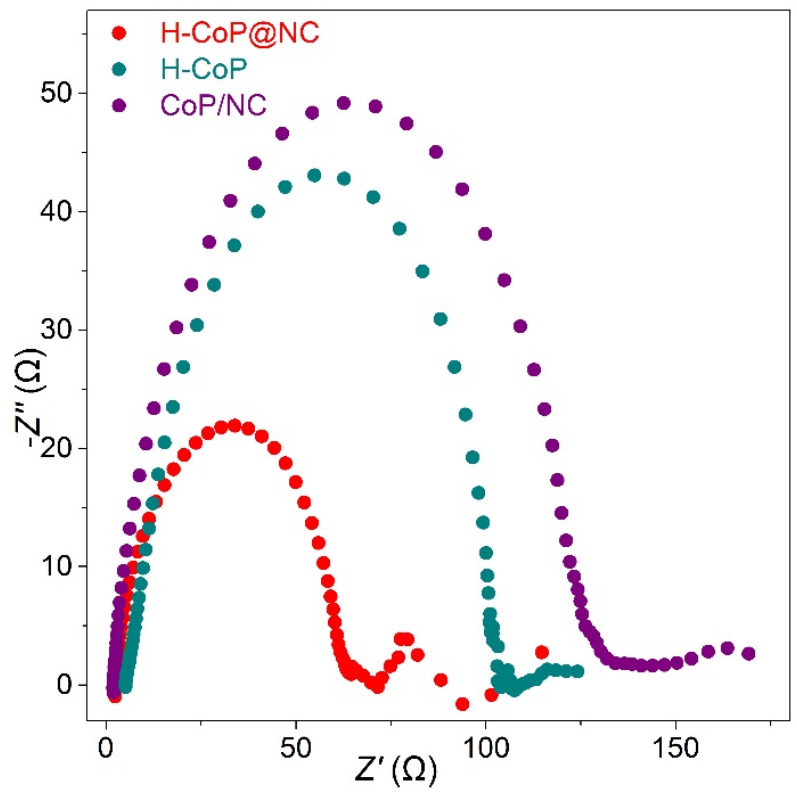

Figure S31. Nyquist plots of H-CoP@NC, H-CoP and CoP/NC for HER in $1.0 \mathrm{M} \mathrm{KOH}(E=-$ $0.20 \mathrm{~V}$ vs. RHE). 
Table S1. Comparison of the performances between the typical cobalt phosphide based bifunctional electrocatalysts for overall water splitting in $1.0 \mathrm{M} \mathrm{KOH}$.

\begin{tabular}{|c|c|c|c|c|c|c|}
\hline \multirow{2}{*}{ Materials } & \multicolumn{2}{|c|}{ Overpotential $\eta_{10}(\mathrm{mV})$} & \multicolumn{2}{|c|}{ Tafel Slope $b(\mathrm{mV} / \mathrm{dec})$} & \multirow{2}{*}{$\begin{array}{c}\text { Full Cell } \\
E(\mathbf{V})\end{array}$} & \multirow{2}{*}{ References } \\
\hline & HER & OER & HER & OER & & \\
\hline $\mathrm{CoP} / \mathrm{rGO}$ & 150 & 340 & 38 & 66 & 1.70 & $\begin{array}{c}\text { Chem. Sci., } \\
\text { 2016. }\end{array}$ \\
\hline $\begin{array}{l}\text { CoP nanorod } \\
\text { (Ni foam) }\end{array}$ & 54 & 300 & 51 & 65 & 1.62 & $\begin{array}{l}\text { Adv Funct } \\
\text { Mater, } \\
2015 .{ }^{\mathrm{s} 6}\end{array}$ \\
\hline $\mathrm{f}-\mathrm{CoP} / \mathrm{CoP}_{2} / \mathrm{Al}_{2} \mathrm{O}_{3}$ & 66 & 300 & 73 & 63 & 1.65 & $\begin{array}{c}\text { Nanoscale, } \\
2017 .{ }^{\mathrm{S} 7}\end{array}$ \\
\hline $\begin{array}{l}\text { CoP-N-C Nanotube } \\
\text { Hollow Polyhedron }\end{array}$ & 115 & 310 & 66 & 70 & 1.64 & $\begin{array}{l}\text { J Am Chem } \\
\text { Soc, 2018. }{ }^{\mathrm{S} 8}\end{array}$ \\
\hline $\begin{array}{c}\text { Carbon Paper/ } \\
\text { Carbon Tubes/CoS } \\
\text { Sheets }\end{array}$ & 190 & 306 & 131 & 72 & 1.74 & $\begin{array}{c}\text { ACS Nano, } \\
2016 .{ }^{\mathrm{s} 9}\end{array}$ \\
\hline CoP-N-MWCNTs & $\begin{array}{c}220 \\
(0.1 \mathrm{M} \mathrm{NaOH})\end{array}$ & $\begin{array}{c}330 \\
(0.1 \mathrm{M} \mathrm{NaOH})\end{array}$ & 56 & 50 & -- & $\begin{array}{c}\text { ACS Appl } \\
\text { Mater } \\
\text { Interfaces, } \\
\text { 2015. }{ }^{\mathrm{S} 10}\end{array}$ \\
\hline $\begin{array}{l}\text { CoP hollow } \\
\text { polyhedron }\end{array}$ & $\begin{array}{c}129 \\
\left(0.5 \mathrm{M} \mathrm{H}_{2} \mathrm{SO}_{4}\right)\end{array}$ & 400 & 59 & 57 & -- & $\begin{array}{c}\text { ACS Appl } \\
\text { Mater } \\
\text { Interfaces, } \\
2016 .{ }^{\mathrm{S} 11}\end{array}$ \\
\hline $\begin{array}{c}\text { Co-P/NC } \\
\text { nanopolyhedrons }\end{array}$ & 154 & 319 & 51 & 52 & 1.71 & $\begin{array}{l}\text { Chem. } \\
\text { Mater. } \\
2015 .^{\mathrm{S} 12}\end{array}$ \\
\hline $\mathrm{Co}-\mathrm{P} / \mathrm{NC} / \mathrm{CC}$ & 171 & 330 & 52 & 61 & 1.77 & $\begin{array}{c}\text { RSC Adv, } \\
2016 .^{\mathrm{S} 13}\end{array}$ \\
\hline H-CoP@NC & 200 & 320 & 71 & 73 & 1.72 & This work \\
\hline
\end{tabular}




\section{Supplementary References}

(S1) Wang, S.; Chen, M.; Xie, Y.; Fan, Y.; Wang, D.; Jiang, J. J.; Li, Y.; Grutzmacher, H.; Su, C. Y. Nanoparticle Cookies Derived from Metal-Organic Frameworks: Controlled Synthesis and Application in Anode Materials for Lithium-Ion Batteries. Small 2016, 12, 2365-2375.

(S2) Liu, Z.; Lu, T.; Song, T.; Yu, X.-Y.; Lou, X. W.; Paik, U. Structure-Designed Synthesis of FeS2@C Yolk-Shell Nanoboxes as a High-Performance Anode for Sodium-Ion Batteries. Energy Environ. Sci. 2017, 10, 1576-1580.

(S3) Jiang, Z.; Li, Z.; Qin, Z.; Sun, H.; Jiao, X.; Chen, D. LDH Nanocages Synthesized with MOF Templates and Their High Performance as Supercapacitors. Nanoscale 2013, 5, 11770-11775.

(S4) Chung, D. Y.; Jun, S. W.; Yoon, G.; Kim, H.; Yoo, J. M.; Lee, K. S.; Kim, T.; Shin, H.;

Sinha, A. K.; Kwon, S. G.; Kang, K.; Hyeon, T.; Sung, Y. E. Large-Scale Synthesis of CarbonShell-Coated FeP Nanoparticles for Robust Hydrogen Evolution Reaction Electrocatalyst. J. Am. Chem. Soc. 2017, 139, 6669-6674.

(S5) Jiao, L.; Zhou, Y. X.; Jiang, H. L. Metal-Organic Framework-Based CoP/Reduced Graphene Oxide: High-Performance Bifunctional Electrocatalyst for Overall Water Splitting. Chem. Sci. 2016, 7, 1690-1695.

(S6) Zhu, Y.-P.; Liu, Y.-P.; Ren, T.-Z.; Yuan, Z.-Y. Self-Supported Cobalt Phosphide Mesoporous Nanorod Arrays: A Flexible and Bifunctional Electrode for Highly Active 
Electrocatalytic Water Reduction and Oxidation. Adv. Funct. Mater. 2015, 25, 7337-7347.

(S7) Li, W.; Zhang, S.; Fan, Q.; Zhang, F.; Xu, S. Hierarchically Scaffolded CoP/CoP2 Nanoparticles: Controllable Synthesis and Their Application as a Well-Matched Bifunctional Electrocatalyst for Overall Water Splitting. Nanoscale 2017, 9, 5677-5685.

(S8) Pan, Y.; Sun, K.; Liu, S.; Cao, X.; Wu, K.; Cheong, W. C.; Chen, Z.; Wang, Y.; Li, Y.; Liu, Y.; Wang, D.; Peng, Q.; Chen, C.; Li, Y. Core-Shell ZIF-8@ZIF-67-Derived CoP Nanoparticle-Embedded N-Doped Carbon Nanotube Hollow Polyhedron for Efficient Overall Water Splitting. J. Am. Chem. Soc. 2018, 140, 2610-2618.

(S9) Wang, J.; Zhong, H. X.; Wang, Z. L.; Meng, F. L.; Zhang, X. B. Integrated ThreeDimensional Carbon Paper/Carbon Tubes/Cobalt-Sulfide Sheets as an Efficient Electrode for Overall Water Splitting. ACS Nano 2016, 10, 2342-2348.

(S10) Hou, C. C.; Cao, S.; Fu, W. F.; Chen, Y. Ultrafine CoP Nanoparticles Supported on Carbon Nanotubes as Highly Active Electrocatalyst for Both Oxygen and Hydrogen Evolution in Basic Media. ACS Appl. Mater. Interfaces 2015, 7, 28412-28419.

(S11) Liu, M.; Li, J. Cobalt Phosphide Hollow Polyhedron as Efficient Bifunctional Electrocatalysts for the Evolution Reaction of Hydrogen and Oxygen. ACS Appl. Mater. Interfaces 2016, 8, 2158-2165.

(S12) You, B.; Jiang, N.; Sheng, M.; Gul, S.; Yano, J.; Sun, Y. High-Performance Overall 
Water Splitting Electrocatalysts Derived from Cobalt-Based Metal-Organic Frameworks. Chem. Mater. 2015, 27, 7636-7642.

(S13) Liu, X.; Dong, J.; You, B.; Sun, Y. Competent Overall Water-Splitting Electrocatalysts Derived from ZIF-67 Grown on Carbon Cloth. RSC Adv. 2016, 6, 73336-73342. 